\title{
Comprehensive analysis of retracted journal articles in the field of veterinary medicine and animal health
}

\author{
Mary M. Christopher
}

\begin{abstract}
Background: Retractions are a key proxy for recognizing errors in research and publication and for reconciling misconduct in the scientific literature. The underlying factors associated with retractions can provide insight and guide policy for journal editors and authors within a discipline. The goal of this study was to systematically review and analyze retracted articles in veterinary medicine and animal health. A database search for retractions of articles with a veterinary/animal health topic, in a veterinary journal, or by veterinary institution-affiliated authors was conducted from first available records through February 2019 in MEDLINE/PubMed, Web of Science, Scopus, Retraction Watch, and Google Scholar. Annual frequency of retractions, journal and article characteristics, author affiliation and country, reasons for retraction, and retraction outcomes were recorded.
\end{abstract}

Results: Two-hundred-forty-two articles retracted between 1993 and 2019 were included in the study. Over this period, the estimated rate of retraction increased from 0.03/1000 to 1.07/1000 veterinary articles. Median time from publication to retraction was 478 days (range 0-3653 days). Retracted articles were published in 30 (12.3\%) veterinary journals and 132 (81.5\%) nonveterinary journals. Veterinary journals had disproportionately more retractions than nonveterinary journals ( $P=.0155)$. Authors/groups with $\geq 2$ retractions accounted for $37.2 \%$ of retractions. Authors from Iran and China published 19.4 and $18.2 \%$ of retracted articles respectively. Authors were affiliated with a faculty of veterinary medicine in 59.1\% of retracted articles. Of 242 retractions, 204 (84.3\%) were research articles, of which $6.4 \%$ were veterinary clinical research. Publication misconduct (plagiarism, duplicate publication, compromised peer review) accounted for $75.6 \%$ of retractions, compared with errors (20.6\%) and research misconduct (18.2\%). Journals published by societies/institutions were less likely than those from commercial publishers to indicate a reason for retraction. Thirty-one percent of HTML articles and 14\% of PDFs were available online but not marked as retracted.

Conclusions: The rate of retraction in the field of veterinary and animal health has increased by $\sim 10$-fold per 1000 articles since 1993, resulting primarily from increased publication misconduct, often by repeat offenders. Veterinary journals and society/institutional journals could benefit from improvement in the quality of retraction notices.

Keywords: Editorial policies, Publication ethics, Publication misconduct, Research misconduct, Veterinary journals

*Correspondence: mmchristopher@ucdavis.edu

School of Veterinary Medicine, University of California-Davis, 4206

VetMed 3A, One Shields Ave, Davis, CA 95616, USA

\section{Background}

Publication and research misconduct are important ethical concerns affecting the integrity of the biomedical literature [1-3]. Retraction of a published article is the primary means by which journals address and communicate scientific misconduct or errors. Retraction is a relatively rare event (estimated by some at $\leq .02 \%[3]$ ), 
but studies have demonstrated an increase in occurrence since about 2000-2001, especially in medical and life science disciplines [3-8]. This increase has been attributed in part to the increasing numbers of journals and scientific articles, which may exceed the capacity of the research community to provide adequate peer review [8]. The proliferation of open-access journals, some of which are low quality, has raised similar questions about peer review as well as whether editorial policies and oversight are adequate to prevent or appropriately handle publication misconduct. Increased retractions are also attributed to increased editor and publisher awareness of the retraction process, development of technological solutions to detect misconduct, shorter times between publication and retraction, and increases in some types of scientific misconduct. Some studies have found that journals with higher impact factors or highly cited articles are retracted more often [3]. Thus, multiple factors and variables can affect retraction rate.

A 2007 survey of science journal editors found that most editors were relatively unconcerned about publication ethics [9]. However, editors of self-published society or institutional journals may have fewer resources or be less aware of best practices for retractions than editors of journals published by commercial publishers. As the focus on publication ethics has increased, the Committee on Publication Ethics (COPE) published best practice guidelines for editors and journals on article retraction, including recommended content for retraction notices [10]. Retraction Watch, a mainstream blog that documents and comments on retractions in the literature, released its database in 2019, facilitating research on retractions [11]. Better understanding of the factors that lead to retractions and their implications for scientists and readers is key to maintaining the integrity of published research.

A focus on retractions by discipline draws attention to sources of error and ethical misconduct relevant to a specific research community and can guide disciplinespecific education and mentoring in scientific research and publishing. Investigations into retractions have been reported for a wide range of biomedical disciplines and medical specialties, including human-subject research [12], cancer [13], surgery [14, 15], emergency medicine [16], dentistry [17], nursing [18], and radiology [19]. Veterinary medicine and animal health research is highly interdisciplinary, encompassing clinical and medical specialties; agriculture and animal science; basic and translational sciences; and wildlife medicine and conservation [20]. Veterinary medicine is also a relatively small field that may be difficult to assess as part of larger retraction studies, especially as veterinary clinicians and scientists publish both in veterinary and nonveterinary journals.
A comprehensive review of retractions in veterinary medicine and animal health could be valuable for understanding the reasons, characteristics, and outcomes of retracted articles in the field and for improving processes that facilitate identification of errors and correction of the literature.

The goal of this study was to comprehensively review and analyze retracted articles in the field of veterinary medicine and animal health. The frequency of retractions, journal and article characteristics (including impact factor, topic, and species focus), author affiliations, reasons for retraction, and retraction outcomes and trends over time were determined. Additional goals were to compare publisher type, open-access journals, veterinary journals, and veterinary faculty-affiliated authors with other journals and authors. The results of this study will identify sources and trends in errors and in ethical misconduct (research and publication misconduct) and how they are reconciled in the veterinary and animal health literature, providing insight to publishers, journal editors, and authors, including veterinarians and animal health scientists.

\section{Results}

Of 548 citations retrieved, 306 were excluded and 242 were included in the study (Fig. 1). The 242 retracted articles involved veterinary medicine or animal health/ disease $(n=188,77.6 \%)$, were published in a veterinary journal $(n=57,23.5 \%)$, and/or at least one author was affiliated with a veterinary faculty or a veterinary laboratory, department, or institute $(n=178,73.5 \%)$. Two-hundred-twenty of $242(90.9 \%)$ retracted articles were indexed in MEDLINE or were in PubMed Central, including 141 from the initial PubMed search and 78 retractions identified initially through other databases. Retractions not initially identified in PubMed occurred prior to 2013 when affiliations were included only for the first author; 12 retracted articles from other databases that were found in PubMed were not identified as retracted.

Of the 242 database citations for retracted articles, 201 were labeled as retracted, 1 was labeled as partially retracted, and 40 were labeled as withdrawn. Withdrawn articles are generally defined as articles retracted while in press or after early online publication, but use of the term was sometimes inconsistent: eight articles identified as retracted in the database were identified at the journal or article level as withdrawn; and 10 articles identified as withdrawn were identified at the journal or article level as retracted. Year of retraction was based on the electronic retraction date (when available) or the print retraction date; a date of retraction was not found for 14 articles. Six of the 14 articles (42.8\%) without a date 


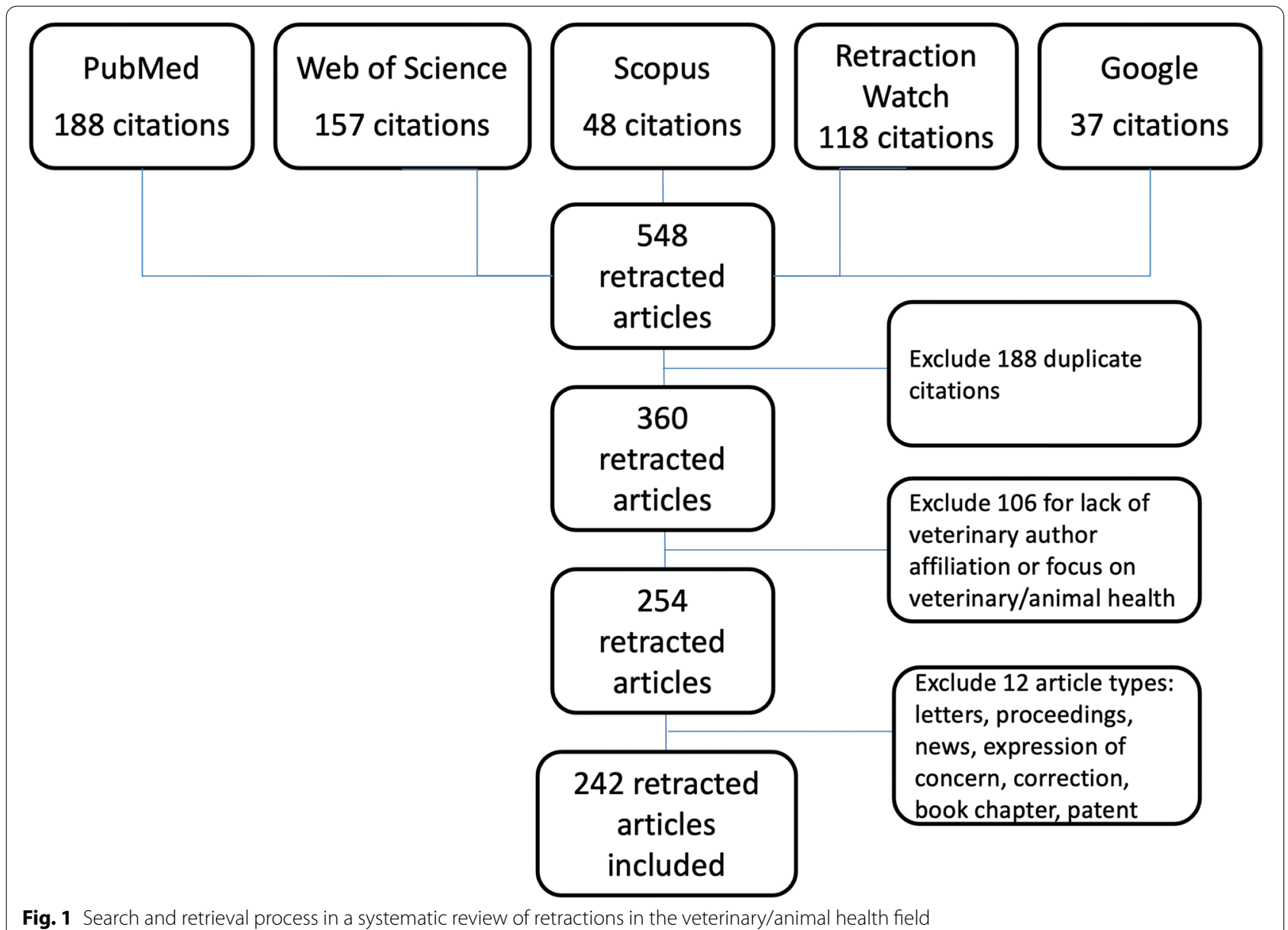

of retraction were in unindexed journals found only in Google (of articles with a date of retraction, only 16/228 or $7.0 \%$ were not indexed). The number of retractions per year from 1993 through 2018 ranged from 0 to 48 (Fig. 2), with none found in 1995-2001 or in 2003. Three retracted articles identified in Jan-Feb 2019 were not included in annual frequency analyses. The annual number of retractions was $<10$ in all years prior to 2012 and $>10$ in all years after 2012, with a peak in 2016. Retraction rate was calculated using the total number of 'veterinary' articles in PubMed, divided into four year-groups, each with approximately equal numbers of articles. The frequency of retractions increased from 0.03/1000 (1993-2003) to $0.37 / 1000(2004-2011)$ to $0.91 / 1000(2012-2015)$ to $1.07 / 1000$ (2016-2018), with an overall retraction rate of 0.56/1000 articles. Frequency was not calculated for 2019 because the full year was not represented.

\section{Journals and publishers}

The 242 retractions were published in 162 unique journals published by commercial publishers, self-published by societies/institutions, or society journals hosted on a publisher website (Table 1). Thirty were categorized as veterinary journals by at least one major index. Veterinary journals had disproportionately more retractions than nonveterinary journals $(P=.0155$, Wilcoxon), accounting for $23.5 \%$ of retractions but only $12.3 \%$ of journals (Table 1). Forty-five (27.8\%) journals were defined on their website as open-access. No significant difference was found in access or publisher type between veterinary and non-veterinary journals $(P>.2505$, Chi square).

Fifteen of $162(9.2 \%)$ journals had $\geq 3$ retractions each, accounting for $31.0 \%(75 / 242)$ of retracted articles (Table 2). Another 20 (12.3\%) journals had 2 retractions each and 127 (78.4\%) journals had 1 retraction each. A significantly higher proportion of veterinary journals (7/30, 23.3\%) had $\geq 3$ retractions compared with nonveterinary journals $(8 / 132,6.1 \%)(P=.0258)$.

One-hundred thirty-three of $162(82.1 \%)$ journals had a 2017 impact factor, with a median of 2.476 (range $0.217-$ 41.058). The median impact factor of veterinary journals 


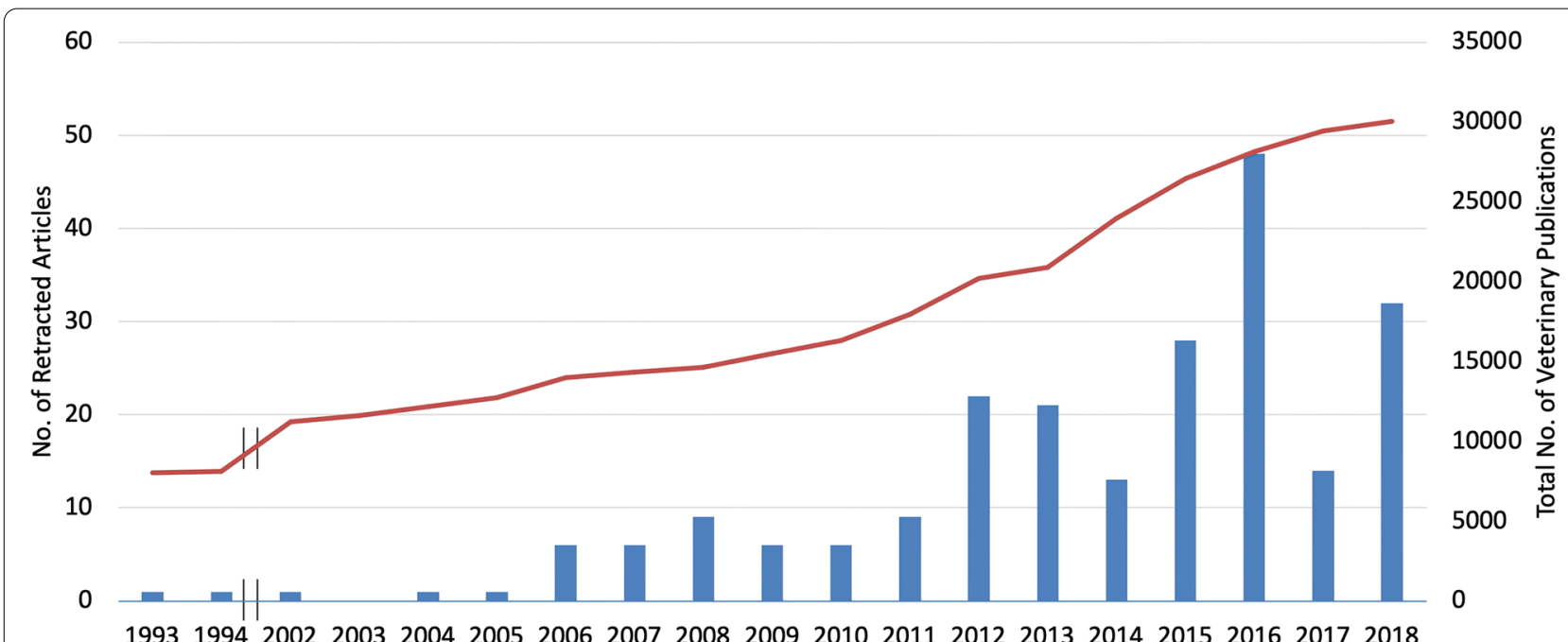

Fig. 2 Total annual number of publications in PubMed using the search term "veterinary" (red line) and the number of retracted articles retrieved in this study (blue bars). No retractions were found from 1995 to 2001 or in 2003

Table 1 Journal characteristics for retracted articles

\begin{tabular}{|c|c|c|}
\hline Characteristic & $\begin{array}{l}\text { No. (\%) Journals } \\
(n=162)\end{array}$ & $\begin{array}{l}\text { No (\%) Retractions } \\
(n=242)\end{array}$ \\
\hline \multicolumn{3}{|l|}{ Indexed By* } \\
\hline MEDLINE & $128(79.0)$ & $200(82.6)$ \\
\hline PubMed Central & $20(12.3) \dagger$ & $20(8.3)$ \\
\hline Science Citation Index & $134(82.7)$ & ND \\
\hline Scopus & $149(91.9)$ & ND \\
\hline \multicolumn{3}{|l|}{ Journal Category } \\
\hline Veterinary & $30(12.3)$ & $57(23.5) \S$ \\
\hline Nonveterinary & $132(81.5)$ & $185(76.4)$ \\
\hline \multicolumn{3}{|l|}{ Publisher Type } \\
\hline Commercial & $110(67.9)$ & $160(66.1)$ \\
\hline Society/institutional & $35(21.6)$ & $57(23.6)$ \\
\hline $\begin{array}{l}\text { Commercial publisher- } \\
\text { hosted societies }\end{array}$ & $17(10.5)$ & $25(10.3)$ \\
\hline \multicolumn{3}{|l|}{ Accessibility } \\
\hline Open-access & $45(27.8)$ & $81(33.5)$ \\
\hline Traditional or hybrid & $117(72.2)$ & $161(66.5)$ \\
\hline
\end{tabular}

*Most journals were found in more than one index so percentages add up to $>100 \%$. PubMed Central is not an index but is included here with MEDLINE to indicate the total retractions retrieved via PubMed

tIncludes 14 complete journals and 6 with select citations, not in MEDLINE $\S$ Significantly higher proportion than nonveterinary journals $(P=.0155$, Wilcoxon)

ND indicates not determined

(1.611, range $0.217-3.285)$ was significantly lower than for nonveterinary journals $(2.734,0.558-41.058)(P<.0001)$. No correlation or difference in impact factor was found among journals based on the number of retractions.

\section{Authors and affiliations}

A total of $143 / 242$ (59.1\%) retractions had faculty of veterinary medicine (FVM)-affiliated authors, of which 107/242 (44.2\%) were first authors (Fig. 3). Retractions with FVM-affiliated (vs other) first authors were significantly more likely to involve companion animals, clinical research, animal models, and animal disease, and were less likely to involve fish or reproductive biology $(P<.03)$. Fifty of $242(20.6 \%)$ retractions had authors affiliated with a veterinary laboratory, department, or institute, of which 26 (52.0\%) were first authors.

First authors were from 37 countries. Iran and China accounted for the most retractions, and together with other top 10 countries accounted for $78.1 \%$ (189/242) of retracted articles (Table 3). Three countries (Italy, Pakistan, Turkey) had 4 retractions each; 5 countries (Australia, Brazil, Gabon, Greece, Thailand) had 3 retractions each; 7 countries (Ethiopia, France, Nepal, Poland, Serbia, South Africa, Switzerland) had 2 retractions each; and 12 countries (Belgium, Canada, Croatia, Czech Republic, Finland, Norway, Philippines, Singapore, Sweden, Taiwan, United Arab Emirates, Vietnam) had 1 retraction each. Compared with other countries, a higher proportion of retracted articles from Spain (14/19) and Iran (39/47) were by authors or author groups with multiple retractions $(P<.0001)$. The country affiliations of co-authors were similar to those of first authors, with 42 unique countries and 9 of the same 10 countries having the most retractions.

Authors or author groups with 2 or more retractions (repeat offenders) accounted for 37.2\% (90/242) of retracted articles (Table 4). Retracted articles by repeat 
Table 2 Journals with 3 or more retracted articles

\begin{tabular}{|c|c|c|c|c|c|}
\hline Journal Title & $\begin{array}{l}\text { No. (\%) of } \\
\text { Retracted } \\
\text { Articles }\end{array}$ & Publisher & $\begin{array}{l}\text { Veterinary } \\
\text { Journal? }\end{array}$ & Open-Access? & $\begin{array}{l}2017 \\
\text { Impact } \\
\text { Factor }\end{array}$ \\
\hline Diagn Pathol & $15(6.2)^{*}$ & Biomed Central & No & Yes & 2.396 \\
\hline PLOS One & $8(3.3)^{*}$ & Public Library of Science & No & Yes & 2.766 \\
\hline Reprod Domest Anim & $7(2.9)^{*}$ & Wiley & Yes & No & 1.422 \\
\hline J Vet Med Sci & $5(2.0)$ & Japanese Society of Veterinary Science & Yes & Yes & 0.803 \\
\hline J Vet Sci & $5(2.0)$ & Korean Society of Veterinary Science & Yes & Yes & 1.327 \\
\hline Tumour Biol & $5(2.0)^{*}$ & $\begin{array}{l}\text { International Society of Oncology and BioMarkers (hosted } \\
\text { by Springer) }\end{array}$ & No & No & - \\
\hline Antioxid Redox Signal & $4(1.6)^{*}$ & Mary Ann Liebert & No & No & 6.540 \\
\hline J Biol Chem & $4(1.6)$ & American Society for Biochemistry and Molecular Biology & No & No & 4.011 \\
\hline Vet Microbiol & $4(1.6)$ & Elsevier & Yes & No & 2.525 \\
\hline Asian-Australasian J Anim Sci & $3(1.2)$ & $\begin{array}{l}\text { Asian-Australasian Association of Animal Production Socie- } \\
\text { ties }\end{array}$ & No & Yes & - \\
\hline J Anim Physiol Anim Nutr & $3(1.2)^{*}$ & Wiley & Yes & No & 1.607 \\
\hline J Clin Microbiol & $3(1.2)$ & American Society of Microbiology & No & No & 4.054 \\
\hline J Med Primatol & $3(1.2)^{*}$ & Wiley & Yes & No & 0.432 \\
\hline$J$ Parasit Dis & $3(1.2)^{*}$ & Indian Society for Parasitology (hosted by Springer) & No & No & - \\
\hline Res Vet Sci & $3(1.2)$ & Elsevier & Yes & No & 1.616 \\
\hline
\end{tabular}

"All or most retractions by "repeat offenders" (see Table 4)

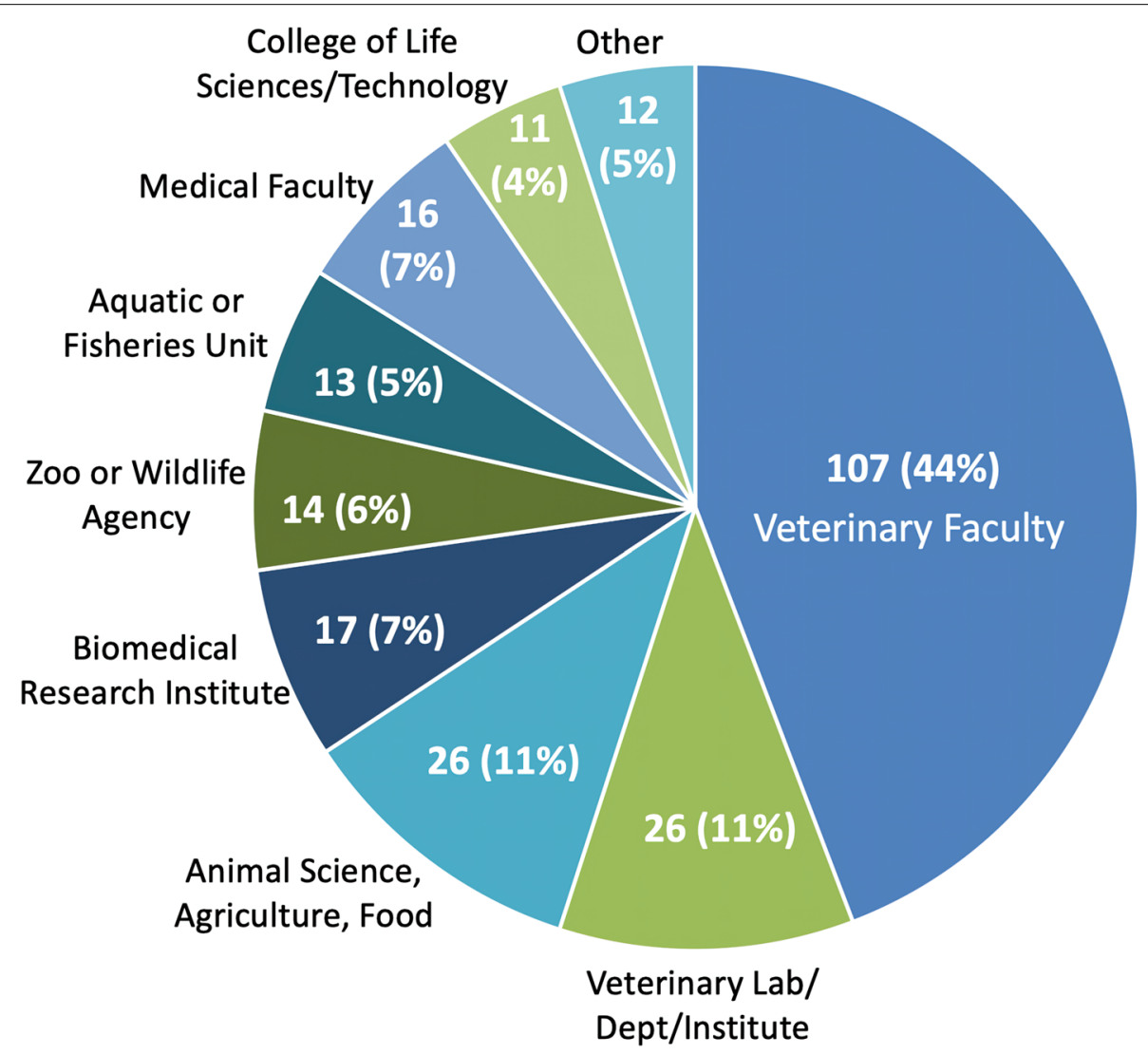

Fig. 3 Institutional affiliation of the first author in 242 retracted articles in the veterinary/animal health field 
Table 3 Top ten countries with retracted articles based on the affiliation of the first author and the reason for retraction

\begin{tabular}{llllll}
\hline Country & $\begin{array}{l}\text { No. (\%) of } \\
\text { retracted } \\
\text { articles }\end{array}$ & \multicolumn{4}{c}{ Reason(s) for Retraction* } \\
\cline { 3 - 6 } & Error & $\begin{array}{l}\text { Research } \\
\text { misconduct }\end{array}$ & $\begin{array}{l}\text { Publication } \\
\text { misconduct }\end{array}$ & Unknown \\
\hline Iran & $47(19.4)$ & 2 & 1 & $40+$ & 3 \\
China & $44(18.2)$ & 8 & 4 & 26 & 8 \\
Korea & $19(7.8)$ & 3 & 6 & 8 & 2 \\
Spain & $19(7.8)$ & 2 & $15+$ & 5 & 2 \\
USA & $18(7.4)$ & $10+$ & 4 & 2 & 2 \\
India & $13(5.4)$ & 1 & 0 & 8 & 4 \\
UK & $10(4.1)$ & 5 & 1 & 2 & 2 \\
Germany & $7(2.9)$ & 1 & 2 & 3 & 1 \\
Egypt & $6(2.5)$ & 0 & 1 & 4 & 2 \\
Japan & $6(2.5)$ & 2 & 1 & 1 & 2 \\
\hline
\end{tabular}

* Some articles were retracted for both research and publication misconduct, so numbers may add up to more than the total number of articles for that country tSignificantly different from other countries in the Table $(P<.0001$, Chi square); for Iran and Spain, these values include multiple retractions by the same author or author group (see Table 4)

offenders were overrepresented in journals with $\geq 3$ retractions $(44 / 75,58.7 \%)$ and underrepresented in journals with only 1 retraction $(29 / 127,22.8 \%)(P<.0001)$. Retractions by repeat offenders accounted for a higher proportion of retractions due to publication misconduct $(59 / 108,54.6 \%)$ and a lower proportion of retractions due to errors $(3 / 43,7.0 \%)(\mathrm{P}<.0001)$. A higher proportion of retractions by repeat offenders were published in nonveterinary $(77 / 90,85.6 \%)$ vs veterinary journals $(13 / 90$, $14.4 \%)(P=.0083)$.

\section{Article types, topics, and species focus}

Most (84.3\%) retractions were research articles, with fewer case reports/case series and review articles (Table 5). Nearly half of retracted research articles involved basic research while only $6.4 \%$ involved veterinary clinical research. The most frequent topic of retracted articles was animal disease or animal disease investigations. Fourteen percent $(35 / 242)$ of retracted articles had public health significance, with a focus on zoonotic disease, antimicrobial/drug residues, environmental toxicology, or food safety. Use of live animals (or their freshly harvested cells or tissues) was described in 181 retracted articles, including laboratory animals from institutional vendors $(n=76,42.0 \%)$, free-ranging wildlife $(n=27,14.9 \%)$, client-owned pets $(n=23,12.7 \%)$, private or commercial farm animals $(n=16,8.8 \%)$, institutional herds or colonies $(n=10,5.5 \%)$, aquacultured fish $(6,3.3 \%)$, abbatoirs $(n=3,1.6 \%)$, and zoos $(n=2$, $1.1 \%)$. Twelve $(6.6 \%)$ articles did not state the source of animals used. Six (3.3\%) articles used human subjects or donors.

\section{Retraction reasons and outcomes}

The median time interval between publication and retraction was 477.5 days (rangew 0-3653 days, $n=228$ ). Commercial publisher-hosted society journals had a significantly longer interval to retraction (median 789.5 days) compared with commercial publishers (243.5 days) and society/institutional publishers (472.5 days) $(P=.0296)$. No significant difference in time to retraction was found for open-access or veterinary journals. Median days to retraction was significantly shorter for articles labeled withdrawn (0 days, range 0-1602 days) as compared with those labeled retracted (701 days, range 0 -3653 days) $(P<.0001)$. No correlation was found between the time to retraction and journal impact factor.

Reasons were provided for retraction in 207/242 (85.5\%) articles (Table 6). The most frequent reason stated was publication misconduct, followed by research misconduct and errors (by the journal or by authors). Median time from publication to retraction was significantly shorter for retractions due to errors (273 days) as compared to publication misconduct (641 days), research misconduct (927 days), or both publication and research misconduct (1614 days) $(P<.0001)$. A significantly higher proportion of veterinary journals did not state the reason for retraction $(17 / 57,29.8 \%)$ compared with nonveterinary journals $(18 / 185,9.7 \%)(P<.0001)$. A higher proportion of journals published by societies/institutions did not state the reason for retraction $(16 / 57,28.0 \%)$ compared with commercial publishers (19/160, 11.9\%) $(P=.0013)$. No difference was found in the reason for retraction between open-access and non-open-access journals. Median journal impact factor was significantly higher for articles retracted for research misconduct (4.011) compared with those retracted for errors (2.525) or publication misconduct $(2.275)(P<.0001)$.

Formal investigations were conducted of 24 authors or author groups involving 65 retracted articles; 9 of the investigated authors were repeat offenders (Table 4). External investigations by universities $(n=11)$, government agencies $(n=2)$, and industry $(n=1)$ were conducted primarily in cases involving research misconduct; formal internal investigations by journals or publishers (7 veterinary and 7 nonveterinary journals) were conducted, primarily for cases of publication misconduct (Fig. 4).

The party initiating retraction was indicated in $227 / 242$ (93.8\%) of retraction notices; of these 14 indicated "author and/or editor" so the initiating party was not clear (Table 7). Authors, all or in part, initiated $43.3 \%$ $(105 / 242)$ of retractions (including $91.4 \%$ of retractions 
Table 4 Authors and author groups with 2 or more retractions (repeat offenders)

\begin{tabular}{|c|c|c|c|c|c|}
\hline Initials of Author/Group & Country & Faculty or Dept & $\begin{array}{l}\text { No. Retractions } \\
\text { /No. Journals }\end{array}$ & Reason(s) for Retraction & $\begin{array}{l}\text { Formal Investigation } \\
\text { Conducted }\end{array}$ \\
\hline $\begin{array}{l}\text { JJ et al. ( } 40+\text { authors in } \\
\text { var. combinations) }\end{array}$ & Iran & FVM & $28 / 8$ & $\begin{array}{l}\text { Compromised peer review, } \\
\text { authorship irregularity, pla- } \\
\text { giarism }\end{array}$ & $\begin{array}{l}\text { Internal investigation by a jour- } \\
\text { nal that published and retracted } \\
15 \text { of the articles }\end{array}$ \\
\hline$J A L$ & Spain & Natural Science Museum & $12 / 7$ & $\begin{array}{l}\text { Distrust data integrity/validity, } \\
\text { authorship irregularity }\end{array}$ & $\begin{array}{l}\text { External investigation by Span- } \\
\text { ish Superior Council of Scientific } \\
\text { Research }\end{array}$ \\
\hline MSA et al. & Iran & Dept of Fisheries & $9 / 2$ & Compromised peer review & $\begin{array}{l}\text { External investigation by uni- } \\
\text { versity; internal investigation by } \\
\text { two journals }\end{array}$ \\
\hline SKK & Korea & FVM & $5 / 2$ & Data fabrication/falsification & $\begin{array}{l}\text { External investigation requested } \\
\text { of author's university }\end{array}$ \\
\hline HK & Korea & Animal Science & $5 / 4$ & Duplicate publication & $\begin{array}{l}\text { Investigations by publisher } \\
\text { (Korean Soc Animal Repro), ethi- } \\
\text { cal committee of journal }\end{array}$ \\
\hline OP & UK & FVM & $4 / 3$ & $\begin{array}{l}\text { Found erroneous data/ analy- } \\
\text { sis (author error) }\end{array}$ & None \\
\hline NDA & Greece & Food Science & $3 / 3$ & Duplicate publication & None \\
\hline EM & Gabon & Medical Research Institute & $3 / 1$ & Plagiarism & None \\
\hline KPA & Nepal & Animal Science & $2 / 2$ & $\begin{array}{l}\text { Duplicate submission and } \\
\text { publication }\end{array}$ & None \\
\hline$J L C-G^{*}$ & Spain & Medical Faculty & $2 / 1$ & Image manipulation & None \\
\hline SC & China & State Lab of Vet Biotech & $2 / 2$ & $\begin{array}{l}\text { Distrust data integrity/ valid- } \\
\text { ity, authorship irregularity, } \\
\text { plagiarism }\end{array}$ & None \\
\hline WSH & Korea & FVM & $2 / 1$ & Data fabrication/ falsification & $\begin{array}{l}\text { External investigation by } \\
\text { author's university }\end{array}$ \\
\hline SL & China & Vet Res Institute & $2 / 2$ & Duplicate publication & None \\
\hline ZXN, DL & China & FVM & $2 / 2$ & Plagiarism & $\begin{array}{l}\text { Internal investigation by affected } \\
\text { journal }\end{array}$ \\
\hline MAN & Iran & Animal Science & $2 / 2$ & $\begin{array}{l}\text { Duplicate submission \& publi- } \\
\text { cation, plagiarism }\end{array}$ & None \\
\hline $\mathrm{FS}, \mathrm{ZW}$ & China & Animal Science & $2 / 2$ & Plagiarism & $\begin{array}{l}\text { External investigation by univer- } \\
\text { sity of plagiarized investigator }\end{array}$ \\
\hline $\mathrm{RT}^{\mathrm{a}}$ & Italy & Vet \& Animal Science & $2 / 2$ & $\begin{array}{l}\text { Data fabrication/ falsification, } \\
\text { image manipulation }\end{array}$ & $\begin{array}{l}\text { External investigation by } \\
\text { author's university; internal } \\
\text { investigation by one journal }\end{array}$ \\
\hline MY & Pakistan & FVM & $2 / 2$ & $\begin{array}{l}\text { Plagiarism, authorship irregu- } \\
\text { larity }\end{array}$ & $\begin{array}{l}\text { No formal investigation but } \\
\text { external inquiries into } 1 \text { article }\end{array}$ \\
\hline
\end{tabular}

${ }^{*}$ Additional articles published by this author/group were retracted from the literature, but the articles had insufficient relevance to the veterinary/animal health field and did not meet inclusion criteria for this study

FVM indicates Faculty of Veterinary Medicine

involving errors); while editors and/or publishers initiated $44.6 \%(108 / 242)$ of retractions. A higher proportion of veterinary $(7 / 53,13.2 \%)$ vs nonveterinary journals $(8 / 175,4.6 \%)$ did not specify who initiated retraction $(P=.0244)$. Similarly, a higher proportion of society/ institutional-published journals $(8 / 57,14.0 \%)$ vs commercial publishers $(7 / 146,4.8 \%)$ did not specify who initiated retraction $(P=.0021)$. Higher proportions of retractions were initiated by editors/publishers (vs authors) in openaccess journals (58.0\% vs $34.5 \%)$ and in cases of publication misconduct $(62.6 \%$ vs $32.1 \%)(P<.01)$.
A majority of retracted articles (182/242, $75.2 \%)$ were accompanied by either a descriptive retraction notice or a link to a retraction notice. Society/institutional publishers were more likely than commercial publishers to simply state 'retracted' in the article title rather than provide a descriptive retraction notice $(P=.0009)$. Forty-five percent (110/242) of HTML articles lacked any indication of retraction or had been removed from the website; $31.4 \%$ $(101 / 242)$ of PDFs lacked any indication of retraction or had been removed from the journal website. A higher proportion of open-access journals $(18 / 81,22.2 \%)$ had 
Table 5 Characteristics of retracted articles in the field of veterinary medicine/animal health

\begin{tabular}{|c|c|c|}
\hline Characteristic & $\begin{array}{l}\text { No. (\%) of Retractions in } \\
\text { Category }\end{array}$ & $\begin{array}{l}\text { No. (\%) of First Authors } \\
\text { at FVM or Vet Dept/Lab/ } \\
\text { Institute }\end{array}$ \\
\hline \multicolumn{3}{|l|}{ Type of Article $(n=242)$} \\
\hline Case reports/case series & $20(8.2)$ & $17 / 20(85.0)$ \\
\hline Hypothesis & $1(0.4)$ & 0 \\
\hline Research & $204(84.3)$ & 105/204 (51.5) \\
\hline Reviews & $17(7.0)$ & 10/17 (58.8) \\
\hline \multicolumn{3}{|l|}{ Type of Research $(n=204)$} \\
\hline Applied & $39(19.1)$ & $15 / 39(38.5)$ \\
\hline Basic & $92(45.1)$ & $51 / 92(55.4)$ \\
\hline Clinical (veterinary) & $13(6.4)$ & $12 / 13(92.3)$ \\
\hline Clinical (human) & $4(2.0)$ & $1 / 4(25.0)$ \\
\hline Epidemiology/field & $31(15.2)$ & $11 / 31(35.5)$ \\
\hline Translational animal model & $24(11.7)$ & $14 / 24(58.3)$ \\
\hline Unknown & $1(0.5)$ & $1(100)$ \\
\hline \multicolumn{3}{|l|}{ Veterinary/Animal Health Topic $(n=188)$} \\
\hline Anatomy and physiology & $14(7.4)$ & $9 / 14(64.3)$ \\
\hline Behavior and welfare & $2(1.1)$ & $0(0)$ \\
\hline Disease/disease investigation & $97(51.6)$ & $62 / 97(63.9)$ \\
\hline Food safety & $10(5.3)$ & $5 / 10(50.0)$ \\
\hline Genetics (avian) & $2(1.1)$ & $0(0)$ \\
\hline Nutrition & $6(3.2)$ & $1 / 6(16.7)$ \\
\hline Pathology/microbiology/parasitology/immunology & $27(14.4)$ & $11 / 27(40.7)$ \\
\hline Reproduction/reproductive biology & $28(14.9)$ & $10 / 28(35.7)$ \\
\hline Toxicology & $2(1.1)$ & $1 / 2(50.0)$ \\
\hline \multicolumn{3}{|l|}{ Public Health Relevance $(n=35)$} \\
\hline Food safety/drug residues/antimicrobial resistance & 17 (48.6) & $6 / 17(35.3)$ \\
\hline Environmental toxicology & $4(11.4)$ & $0 / 4(0)$ \\
\hline Zoonotic disease & $14(40.0)$ & $6 / 14(42.8)$ \\
\hline \multicolumn{3}{|l|}{ Species Focus $(n=225)$} \\
\hline Avian (all but 1 wildlife) & $19(8.4)$ & $2 / 19(10.5)$ \\
\hline Companion animal (dog, cat, horse) & $35(15.5)$ & $30 / 35(85.7)$ \\
\hline Fish & $17(7.5)$ & $3 / 17(17.6)$ \\
\hline Human & $14(6.2)$ & $6 / 13(46.1)$ \\
\hline Laboratory (mouse, rat, rabbit) & $47(20.9)$ & $33 / 47(70.2)$ \\
\hline Livestock (cattle, pig, sheep, goat, buffalo, camel) & $52(23.1)$ & $31 / 52(59.6)$ \\
\hline Non-human primate & $8(3.5)$ & $2 / 8(25.0)$ \\
\hline Non-domestic (bear, elephant, fox, hare, lynx, opossum, snake) & $7(3.1)$ & $4 / 7(57.1)$ \\
\hline Multiple species & $8(3.5)$ & $4 / 8(50.0)$ \\
\hline Poultry & $18(8.0)$ & $10 / 18(55.5)$ \\
\hline
\end{tabular}

unmarked article PDFs on the journal website compared with non-open-access journals $(16 / 157,10.2 \%)(P=.0234)$.

Retraction outcome data were examined by year group (1993-2011, $n=47 ; 2012-2015, n=84$; 20162018, $n=94$ ) for comparison of trends over time. The percentage of HTML and PDF articles marked as retracted increased significantly in 2016-2018 compared with prior years $(P<.01)$ (Fig. 5). Editors/ journals initiated a higher proportion of retractions in 2016-2018 compared with previous years $(P=.0007)$. Significantly more retractions were the result of research misconduct (vs publication misconduct) in 2012-2015 $(P=.0004)$. Median time from publication to retraction did not differ significantly in 19932011 (302 days) compared to 2012-2015 (409 days) and 2016-18 (686 days) $(P=.1667)$. 
Table 6 Reasons for the retraction of articles in veterinary medicine/animal health

\begin{tabular}{|c|c|c|c|}
\hline Category & Reason & No. (\%) of Retractions ${ }^{*}$ & $\begin{array}{l}\text { Total No. (\%) } \\
\text { Retractions }\end{array}$ \\
\hline \multirow[t]{3}{*}{ Error } & & & $50(20.6 \%)$ \\
\hline & Administrative error by journal or publisher & $13(5.3 \%)$ & \\
\hline & Erroneous data, analysis, or interpretation by author & $37(15.3 \%)$ & \\
\hline \multirow[t]{5}{*}{ Research misconduct } & & & $44(18.2 \%)$ \\
\hline & Data fabrication or falsification & $23(9.5 \%)$ & \\
\hline & Suspected data fabrication/ falsification & $5(2.0 \%)$ & \\
\hline & Image manipulation & $13(5.3 \%)$ & \\
\hline & Research misconduct, not otherwise specified & $3(1.2 \%)$ & \\
\hline \multirow[t]{5}{*}{ Publication misconduct } & & & $183(75.6 \%)$ \\
\hline & Plagiarism, misappropriation of data & $65(26.8 \%)$ & \\
\hline & Duplicate publication ${ }^{\dagger}$ & $41(16.9 \%)$ & \\
\hline & Authorship irregularity & $41(16.9 \%)$ & \\
\hline & Compromised peer review & $36(14.9 \%)$ & \\
\hline Unknown & & & $35(14.4 \%)$ \\
\hline
\end{tabular}

* Retraction notices reporting both research and publication misconduct $(n=11)$ are counted in both categories, so percentages add up to $>100 \%$

${ }^{\dagger}$ Four of 41 retractions for duplicate publication also specified duplicate submission

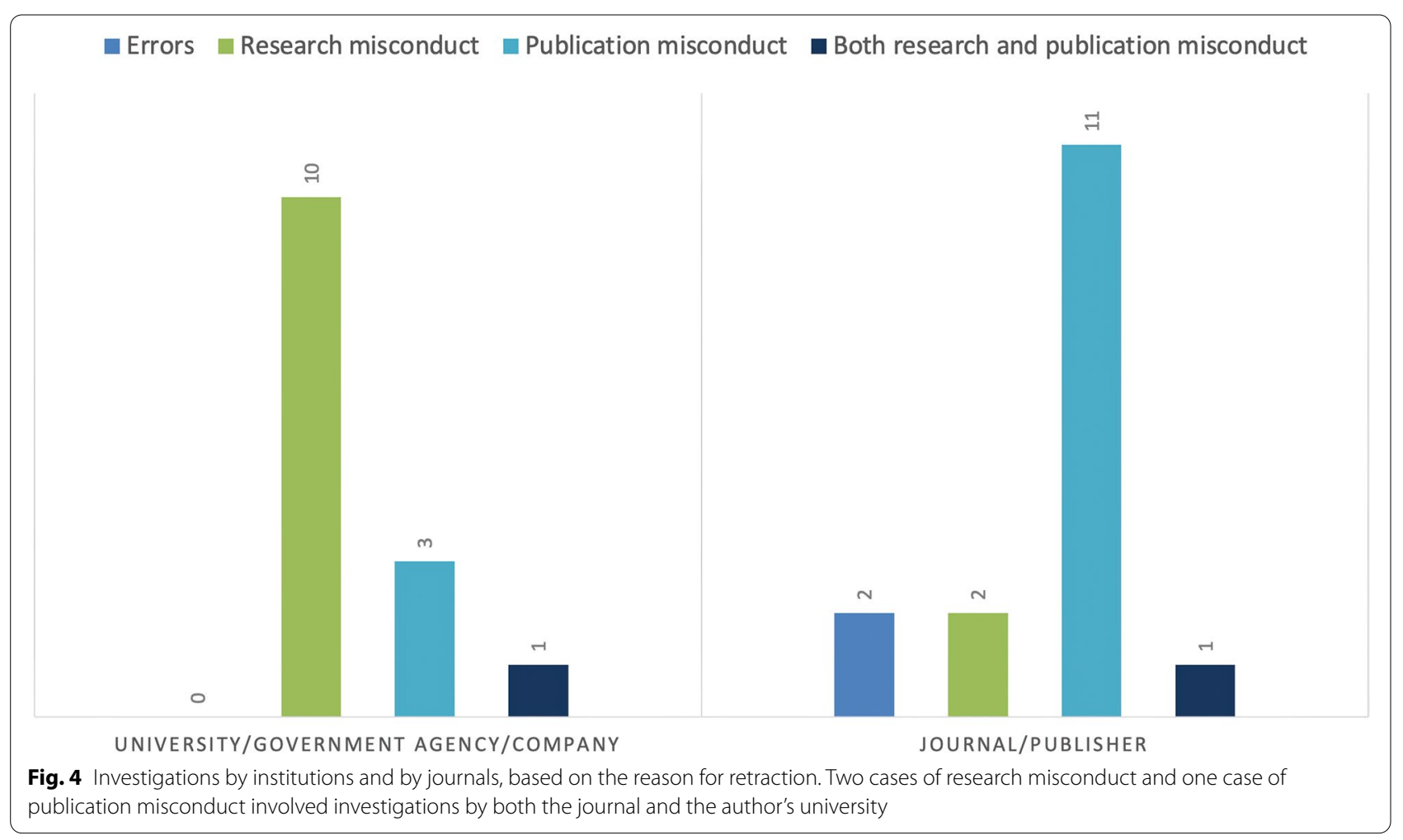

\section{Discussion}

Retractions in the field of veterinary medicine and animal health have increased substantively since 2012, with publication misconduct (especially plagiarism and duplicate publication) accounting for more than $75 \%$ of retracted articles. Notably, a few repeat offenders accounted for a high proportion of total retractions. In part because of this, veterinary journals had significantly more retractions than nonveterinary journals, and together with society/institutional journals, were less likely to provide 
Table 7 Characteristics of retractions in the field of veterinary medicine/animal health

\begin{tabular}{ll}
\hline Characteristic & $\begin{array}{l}\text { No. (\%) of } \\
\text { Retractions }\end{array}$ \\
\hline Initiator of retraction ( $n=242)$ & \\
Author(s) & $59(24.3)$ \\
Author and editor/publisher & $46(19.0)$ \\
Author and/or editor & $14(5.8)$ \\
Editor & $45(18.6)$ \\
Editor and publisher & $39(16.1)$ \\
Publisher & $24(9.9)$ \\
Not specified & $15(6.2)$ \\
Retraction notice on website ( $\mathrm{n}=242)$ & \\
Descriptive retraction notice & $114(47.1)$ \\
Link to descriptive retraction notice & $68(28.1)$ \\
Marked as retracted & $17(7.0)$ \\
No indication of retraction & $43(17.7)$ \\
Full-text HTML article availability and marking ( $\mathrm{n}=242)$ & \\
Available, unmarked & $76(31.4)$ \\
Available, marked as retracted (in title or watermark) & $8133.5)$ \\
Removed, title marked as retracted & $51(21.0)$ \\
Removed, no indication of retraction & $34(14.0)$ \\
PDF article availability and marking ( $\mathrm{n}=242)$ & \\
Available, unmarked & $34(14.0)$ \\
Available, watermarked & $127(52.5)$ \\
Available, includes retraction notice & $10(4.1)$ \\
Removed from journal website & $67(27.7)$ \\
Could not access (PDF behind paywall) & $4(1.6)$ \\
\hline &
\end{tabular}

informative retraction notices. These findings suggest that enhanced editorial oversight of peer review, and timely and transparent recognition of ethical misconduct, could help correct the literature and minimize the societal impact of retractions on the discipline.

Veterinary medicine and animal health is a diverse field that can be challenging to capture in bibliographic analyses. The comprehensive approach used herein included not only the veterinary journal category (across three major indexers for complete coverage), but also retractions with a topical focus on animal health and disease and those with authors at veterinary institutions, many of whom publish in non-veterinary journals. (CAB Abstracts also fully indexes veterinary topics but does not include retractions or retracted articles as a document type for searches so was not used in this study.) Unlike retractions included in the Veterinary Science category of Retraction Watch [21], the present study excluded laboratory animal studies intended solely to inform human health unless they included a veterinary-affiliated author. The result was a robust dataset that is widely representative of the field as well as the diverse work of veterinarians and those engaged in research in veterinary schools and research facilities. The main limitation of the dataset, as in other studies of retractions, was lack of a control group to compare with non-retracted article topics, authors, and journals. However, associations of these variables with the reasons for retraction and retraction outcomes were informative. Unlike larger bibliographic analyses [2, $4,5]$, where veterinary science is inapparent or comprises a small, relatively unexamined subset of retractions, the present study expands our view of the field and thereby improves understanding of discipline-specific factors associated with retractions.

As reported in other bibliographic analyses [3-8], the rate of retraction in the veterinary medicine/animal health literature increased substantively over the study period, with a 10-fold increase (per 1000 articles) since 1993 and acceleration beginning in 2006, slightly later than for life and medical sciences in general $[4,5$, 7]. Compared with some medical specialties (e.g., radiology and emergency medicine) [16, 19], the annual rate of retractions in veterinary medicine/animal health was relatively high, although other studies often used only a single database/index or had small samples sizes. A prevalence of 4/100,000 $(1 / 25,000)$ was reported previously for veterinary science retractions, considerably lower than the estimated 50/100,000 (1/2000) prevalence reported here [2]. That study found only 17 retracted articles in veterinary science through 2011 (compared to 47 in that time period in this study), likely because article categories and prevalence were based solely on the Web of Science. Although PubMed veterinary publications were an imperfect denominator for calculating retraction prevalence, PubMed included a large majority of the retractions found across indexes and thus provided the best available estimate. Although an increase in retractions can result from increased efficiency in the system to correct the literature $[6,7]$, a temporal decrease in the time-to-retraction was not observed in the present study.

Retractions in veterinary medicine and animal health were most frequently the result of publication misconduct, which has been associated with reduced barriers to publication (e.g., lack of rigorous peer review) and inadequate editorial oversight. The proportion of retractions due to plagiarism and duplicate publication combined (44\%) was similar to that reported in other studies and disciplines (42-48\%) [5, 14, 16, 19, 22]. Other studies, on the other hand, have found research misconduct to be the primary cause of retraction [4, 12]. Compromised peer review was associated with two repeat offenders and $15 \%$ of retracted articles in the present study, a rate similar to that in a 2018 study of open-access journals [8]. Plagiarism and duplicate publication have increased since about 2005 [4], while compromised peer review has 


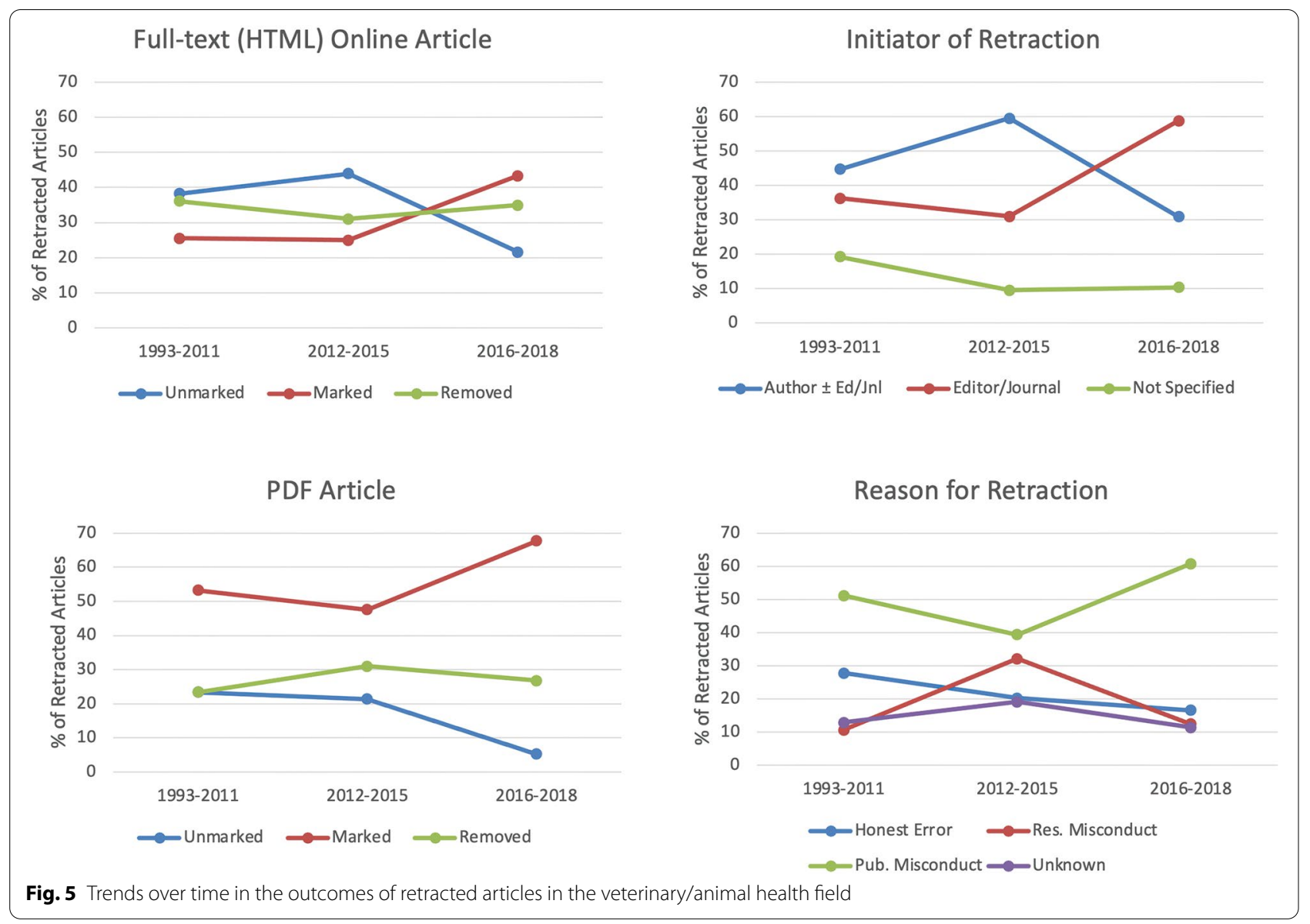

gained attention only more recently, since about 2015 [22, 23]. There is evidence of awareness of publication misconduct within the veterinary research community, with published exchanges in veterinary journals that range from apologetic [24, 25] to accusatory [26]. Such discussion also suggests a willingness to address and resolve issues of publication misconduct within the profession.

Veterinary journals comprised surprisingly few of the journals in this study, perhaps because of the predominance of basic (vs clinical) science articles retracted and because of the lower impact factors or perceived value of veterinary journals compared with other biomedical journals [27, 28]. Although high-impact journals and highly cited articles are retracted more often [3, 4], repeat offenders appeared to have had a disproportionate effect on the incidence of retractions in veterinary journals. Veterinary journals, together with self-published society/institutional journals, also had less informative retraction notices than other journals. These findings suggest weaker editorial processes or policies regarding publication misconduct, or a reluctance to acknowledge and address errors. Editors of small journals may be unaware of international publishing practices [29] and could benefit from stepped-up surveillance for potential misconduct (e.g., plagiarism) and improved retraction notices. That said, even high-impact journals seldom use plagiarism-checking services, and only a third provide authors with definitions of misconduct [30].

Author conduct and publication decisions are influenced by training, mentorship, affiliation, institutional culture, economic incentives, and national and academic ethical policies [2, 3, 23, 31]. In addition, retraction rates may track with overall publication rates, and although Western Europe and North America publish the majority of veterinary articles, publication rates from Asia (India, China), Latin America (Brazil), and the Middle East (Turkey, Iran) have notably increased since 2005 [20]. Authors of most retractions in the present study were from Iran and China, and the top 10 countries were similar to those of other studies $[4,5,8,31,32]$. The pattern of retractions differed, with Iranian authors often involving repeat offenders and peer review, while Chinese authors more often had 1 or at most 2 retractions, usually attributed to plagiarism, but also to errors. The latter finding differed from a study of retractions by Chinese researchers [33], which found a high incidence of repeat offenders and 
faked peer review. Had only authors with single retractions been considered in the present study, China would have ranked first, followed by the USA, India and Iran, and essentially the same top 10 list. India, which ranked 6 th in retraction rate in the present study (5\% of retractions), had the highest ratio of fraudulent to total papers in a study of low- and middle-income countries [31]. Plagiarism and duplicate publication are thought to stem, in part, from the root issue of originality, which can present a particular challenge for authors in some countries [32, 34].

Repeat offenders accounted for nearly $40 \%$ of retractions in veterinary medicine and animal health. Indeed, those with $\geq 5$ retractions comprised nearly $25 \%$ of total retractions, more than double the $10 \%$ expected based on a power-law model of repeating probability [35]. This high proportion of habitual offenders introduced bias into analyses involving country of origin, author affiliation, and article topic. While sometimes viewed as anomalies or outliers [5], repeat offenders also provide unique insight into publication or research misconduct. Of particular note in this study was the Iranian group of repeat offenders. This group was reported previously to have 15 retractions in the online journal Diagnostic Pathology $[8,22]$. In the present study, however, this group was associated with 28 retractions ( $11.5 \%$ of total) in 8 journals involving more than 40 authors in total. In addition, despite the FVM affiliation of many of the authors, none of the retractions was in a veterinary journal. Rather, the retractions included several case studies of common pathologic lesions or tumors in companion animals (e.g., mast cell tumors, mammary neoplasia) that have been well studied in the veterinary literature. Nonveterinary journals are more likely to lack appropriate veterinary content experts, both reviewers and editors, which could explain how the peer review process was repeatedly circumvented. Inadequate peer review practices are associated with retractions; specifically, closer involvement of the Editor-in-Chief and wider community in the review process is related to fewer retractions [36]. However, this alone may not be enough to prevent publication misconduct, as another Iranian repeat offender had multiple retractions in Reproduction in Domestic Animals, a veterinary journal appropriate for the research topic. The proliferation of low-quality, open-access journals can provide opportunity for repeat offenders to exploit new and unsupervised systems [8], but high-quality, open-access journals have also expanded, and the rate of retraction in open-access journals did not differ in the present study. Further, regardless of whether the peer review process was compromised by the authors, absent or inadequate peer review processes can occur if there is insufficient editorial board oversight and integrity.
Retractions reflect a failure to identify problems prior to publication but also signal a willingness on the part of journals and authors to correct mistakes [36]. Retraction notices are the primary means by which ethical breaches in research and publication are communicated to readers, although there is evidence that readers continue to use retracted information [37]. Just as importantly, retractions are intended to "correct" the literature and safeguard its integrity, although the lag from publication to retraction and differences among indexes can create inconsistency and initial confusion $[10,38]$. Per COPE guidelines, retraction notices should be linked to all versions of an article; should clearly identify the retracted article; should clearly identify the action as a retraction; and should be published promptly [10]. Further, consistent language has been proposed for various forms of retractions and corrections [39]. Inconsistent usage of "retraction" and "withdrawal" was observed in a subset of the retractions in this study, and retraction notices were inconsistently linked to the HTML and PDF versions of articles.

It is recommended that a retraction notice also state the parties who initiated, issued, and supported the decision to retract; whether the authors were contacted and agreed to the retraction; the reason(s) for retraction; the sections retracted and the effect on the rest of the article; and the action taken by the journal [10]. Few retraction notices were complete in this regard and the considerable variation, as found in other studies, often made it difficult to ascertain the true cause of a retraction $[3,4,12]$. In some cases editors appeared to relitigate the peer review process and publish extensive external comments and complaints; in other cases articles simply disappeared without notice. Retractions initiated by authors due to errors in data, analyses, or reproducibility tended to have more detailed descriptions of how the integrity of the work was affected. The repeat offender from Spain in the present study was the result of distrust of data integrity and validity on the part of co-authors; retraction notices carefully described the part of the work affected, and those parts that remained credible. Notably in the current study, retraction practices were improved in 2016-18 compared with previous years, continuing a trend of improvement over time [40].

While the scholarly impact of articles and authors decreases after retraction, the societal impact of retractions on the field of veterinary science and public health can be substantive $[4,41]$. Concerns involving contaminated animal feed and animal welfare, discussed extensively on Retraction Watch and in the media, have had significant implications for researchers and for the animal health industry [11]. The extensive external investigations 
initiated in a number of cases in the present study represent one of the more serious sanctions a journal can impose on offending authors [1]. A proposed system for maintaining the integrity of research (REPAIR) focuses on institutional and national responsibility, integrity, and transparency in the interest of creating a positive research culture [42]. Such practices will help maintain public confidence in the scientific literature.

\section{Conclusions}

Retractions of journal articles in the veterinary medicine and animal health literature have increased substantially since 2012, primarily as a result of publication misconduct. Retracted articles reflect the breadth of animal health research and its diverse investigators, including both FVM and nonveterinary affiliations. Repeat offenders have a disproportionate effect on retractions, but recent trends suggest increasing editorial assertion and implementation of policies that better identify retracted literature. The societal impact of retractions on the animal health profession can be minimized through rigorous peer review processes, enhanced editorial oversight, use of digital tools, and the timely identification and transparent description of the error or misconduct.

\section{Methods}

A systematic search for retracted articles was conducted in February 2019 using five databases: PubMed (MEDLINE and PubMed Central), Web of Science (Science Citation Index Expanded), Scopus, Retraction Watch, and Google Scholar. In PubMed, the Web of Science, and Scopus, a search on the term "veterinary" (all fields) was filtered by document type "retracted publications" and "retraction of publication" (and "withdrawal" for PubMed) for the entire time period of available articles (through February 2019). In Retraction Watch, retracted articles in the topic field "(HSC) Veterinary Science" were retrieved [21]. Google Scholar and Google were searched using variations on the terms "veterinary" and "retraction"; the first 25 pages of entries were examined or until 5 sequential pages yielded no relevant entries.

Retracted articles in English were included if they met at least one of the following inclusion criteria: (1) the article was published in a journal indexed as a "veterinary"

Table 8 Definition of variables in a systematic analysis of retractions in the field of veterinary medicine/animal health

\begin{tabular}{|c|c|}
\hline Variables & Definition \\
\hline \multicolumn{2}{|l|}{ Journals } \\
\hline Journal title & - \\
\hline Publisher & Commercial, society/institutional, commercial publisher-hosted society \\
\hline Open-access & Yes/no \\
\hline Indexing & MEDLINE, Science Citation Index (SCI), Scopus \\
\hline Veterinary journal & Indexed in "VET" category in one or more indexes \\
\hline Impact factor & Based on 2017 Journal Citation Report \\
\hline \multicolumn{2}{|l|}{ Articles } \\
\hline Publication date & Electronic and print publication dates \\
\hline Article title & - \\
\hline \multirow[t]{3}{*}{ Authors } & First author affiliation and country \\
\hline & Co-author(s) affiliation and country \\
\hline & Repeat offender (author or author group with $\geq 2$ retractions) \\
\hline Article type & Research, review, case report/series, other \\
\hline \multirow[t]{5}{*}{ Research type/topic } & Basic, applied, clinical, epidemiology/field, translational model \\
\hline & Veterinary/animal health topic (e.g., pathology, medicine) \\
\hline & Public health relevance (yes/no) \\
\hline & Animal species involved \\
\hline & Live animal source (e.g., lab animal, wildlife, client-owned) \\
\hline \multicolumn{2}{|l|}{ Retractions } \\
\hline Retraction date & Electronic and print retraction dates \\
\hline Time to retraction & Time interval between publication and retraction (days) \\
\hline Reason for retraction & Error, research misconduct, publication misconduct \\
\hline Initiated retraction & Author(s), editor, journal, publisher, combination \\
\hline Investigation & Internal (journal) or external (institutional) investigation \\
\hline \multirow[t]{2}{*}{ Outcomes } & HTML article: Available? Watermark? Retraction notice? \\
\hline & PDF article: Available? Watermark? Retraction notice? \\
\hline
\end{tabular}


journal by MEDLINE, Science Citation Index, or Scopus; (2) at least one of the authors was affiliated with a faculty (school/college) of veterinary medicine (FVM), or with a veterinary laboratory, department, or institute; and (3) the article involved veterinary medicine or animal health/disease (excluding invertebrates, but including fish and wildlife). When retraction notices listed additional articles by the same author(s) that had not already been retrieved in the search process, the additional articles were examined and added to the study if they met one or more of the inclusion criteria. Withdrawn articles, defined as articles retracted while in press or after early online publication, were included because of inconsistent and sometimes interchangeable use of the terms 'retraction' and 'withdrawal' by journals and indexers [39]. Articles were excluded if: (1) laboratory animals were used solely as a model of human disease and without a veterinary-affiliated author; (2) the author's institutional affiliation included "Veterinary" only in a broader context (e.g., College of Medical, Veterinary, and Life Sciences) and otherwise lacked specific veterinary affiliation; (3) the term "veterinary" occurred solely in the cited literature of the article; and (4) the article was erroneously retrieved because it contained similar but irrelevant terms (e.g., "Veterans"). Retracted news articles, book chapters, commentary, corrigenda, and letters to the editor also were excluded.

Articles were given a unique identifier and the original citation and source (index) were recorded. PubMed was used as the core source; retraction records found initially in Web of Science, Scopus, Retraction Watch, and Google were subsequently also searched for in PubMed. Because more than $90 \%$ of retracted articles ultimately were found in PubMed, the PubMed dataset of "veterinary" articles was used to estimate the prevalence of retractions. Retracted articles, journal websites, and retraction notices were retrieved and examined. Data were recorded for variables associated with the journal, the article, and the retraction notice (Table 8). Journals were categorized as open-access if the journal website stated that it was an open-access journal, with all articles free to the public. Publisher type was categorized as commercial publishers, society/institutional publishers, and commercial publishers that hosted a society journal. Classification of article type (i.e., research, review, case report/case series) was based on article content. The affiliation and country of the first author and co-authors were recorded.

\section{Statistical analysis}

Data were compiled in an Excel spreadsheet (Microsoft v 2019, Redmond, WA, USA) and analyzed statistically using JMP software (version 15.0, SAS Institute, Inc., Cary NC, USA). Based on visual assessment and the
Anderson-Darling goodness-of-fit test, distribution of continuous variables (impact factor, days to retraction, number of retractions, number of authors) was found to be non-Gaussian. Therefore, those quantitative results were expressed as median and range (minimum-maximum values) and the nonparametric Wilcoxon rank sum test was used to compare results between groups. Categorical variables were expressed as frequency (\%), and proportions were compared using Chi-square analysis. A $P$ value of $<.05$ was considered as significant.

\section{Supplementary Information}

The online version contains supplementary material available at https://doi. org/10.1186/s12917-022-03167-x.

Additional file 1. Retracted articles included in this study.

Acknowledgments

Not applicable.

Author's contributions

MMC designed and conducted the study and wrote the manuscript. The author has read and approved the final manuscript.

Funding

No funding was obtained for this study.

Availability of data and materials

The datasets used and/or analyzed during the current study are available from the corresponding author on reasonable request.

\section{Declarations}

Ethics approval and consent to participate Not applicable.

Consent for publication

Not applicable.

Competing interests

The author declares that she has no competing interests.

Received: 12 July 2021 Accepted: 24 January 2022

Published online: 18 February 2022

References

1. Benos DJ, Fabres J, Farmer J, Gutierrez JP, Hennessy K, Kosek D, et al. Ethics and scientific publication. Adv Physiol Educ. 2005;29:59-74.

2. Zhang M, Grieneisen. The impact of misconduct on the published medical and non-medical literature, and the news media. Scientometrics. 2013;96:573-87.

3. Hesselmann F, Graf V, Schmidt M, Reinhart M. The visibility of scientific misconduct: a review of the literature on retracted journal articles. Curr Sociol Rev. 2017;65(6):814-45.

4. Fang FC, Steen RG, Casadevall. Misconduct accounts for the majority of retracted scientific publications. PNAS. 2012;109(42):17028-33.

5. Grieneisen M, Zhang M. A comprehensive survey of retracted articles from the scholarly literature. PLoS One. 2012;7(10):e44118.

6. Steen RG, Casadevall A, Fang FC. Why has the number of scientific retractions increased? PLoS One. 2013;8(7):e68397.

7. Fanelli D. Why growing retractions are (mostly) a good sign. PLoS Med. 2013;10(12):e1001563. 
8. Wang T, Xing Q-R, Wang H, Chen W. Retracted publications in the biomedical literature from open access journals. Sci Eng Ethics. 2018. https:// doi.org/10.1007/s11948-018-0040-6.

9. Wager E, Fiack S, Graf C, Robinson A, Rowlands I. Science journal editors' views on publication ethics: results of an international survey. J Med Ethics. 2009;35:348-53.

10. Committee on Publication Ethics. Guidelines for retracting articles. https://doi.org/10.24318/cope.2019.1.4. Accessed Dec 3, 2019.

11. Retraction Watch. Retraction Watch database user guide. https://retra ctionwatch.com/retraction-watch-database-user-guide/. Accessed Dec 3, 2019.

12. Li G, Kamel M, Jin Y, et al. Exploring the characteristics, global distribution and reasons for retraction of published articles involving human research participants: a literature survey. J Multidiscip Healthc. 2018;11:39-47.

13. Bozzo A, Bali K, Evaniew N, Ghert M. Retractions in cancer research: a systematic survey. Res Integr Peer Rev. 2017;2:5.

14. King EG, Oransky I, Sachs TE, et al. Analysis of retracted articles in the surgical literature. Am J Surg. 2018;216:851-5.

15. Dell'Acqua Cassao B, Herbella FAM, Schlottmann F, Patti MG. Retracted articles in surgery journals. What are surgeons doing wrong? Surgery. 2018;163:1201-6.

16. Chauvin A, De Villelongue C, Pateron D, Yordanov Y. A systematic review of retracted publications in emergency medicine. Eur J Emerg Med. 2019:26:19-23. https://doi.org/10.1097/MEJ.0000000000000491.

17. Faggion CM, Ware RS, Bakas N, Wasiak J. An analysis of retractions of dental publications. J Dentistry. 2018;79:19-23. https://doi.org/10.1016/j. jdent.2018.09.002.

18. Al-Ghareeb A, Hillel MKL, Cleary M, Visentin D, Jones M, Bressington D, et al. Retraction of publications in nursing and midwifery research: a systematic review. Int J Nurs Stud. 2018;81:8-13.

19. Rosenkrantz AB. Retracted publications within radiology journals. Am J Radiol. 2016;206:231-5.

20. Christopher MM, Marusic A. Geographic trends in research output and citations in veterinary medicine: insight into global research capacity, species specialization, and interdisciplinary relationships. BMC Vet Res. 2013:9:115. http://www.biomedcentral.com/1746-6148/9/115.

21. Retraction Watch. Category: veterinary science. http://www.retraction watch.com/category/by-subject/veterinary-science/. Accessed Dec 3, 2019.

22. Moylan EC, Kowalczuk MK. Why articles are retracted: a retrospective cross-sectional study of retraction notices at BioMed central. BMJ Open. 2016:6:e012047. https://doi.org/10.1136/bmjopen-2016-012047.

23. Rivera $\mathrm{H}$. Fake peer review and inappropriate authorship are real evils. J Korean Med Sci. 2019;34(2):e6. https://doi.org/10.3346/jkms.2019.34.e6.

24. Bristol DG. Unintentional duplicate reporting of equine enterocutaneous fistulae [letter]. Vet Surg. 1994;23:534.

25. Retraction Watch. "Absolutely mortified" after unintentionally plagiarizing, author offers to step down from new post. https://www.retractionwatch. com/2018/03/27/absolutely-mortified-after-unintentionally-plagiarizingauthor-offers-to-step-down-from-new-post/. Accessed June 25, 2021

26. Rabozzi R, Oricco S, Meneghini C, Franci P. Using ideas and methodologies from other authors without proper referencing is a form of plagiarism! [letter, with response from Kwak J et al]. Vet Radiol Ultrasound. 2018:59:135-6.

27. Christopher MM. One health, one literature: weaving together veterinary and medical research. Sci Transl Med. 2015;7:303fs36. https://doi.org/10. 1126/scitrans/med.aab0215.

28. Christopher MM. Weighing the impact (factor) of publishing in veterinary journals. J Vet Cardiol. 2015;17:77-82.

29. Grindlay DJC, Dean R, Christopher MM, Brennan ML. A survey of the awareness, knowledge, policies and views of veterinary journal editorsin-chief on reporting guidelines for publication of research. BMC Vet Res. 2014;10:10.

30. Bosch X, Hernandez C, Pericas JM, Doti P, Marusic A. Misconduct policies in high-impact biomedical journals. PLoS One. 2012;7(12):e51928.

31. Ana J, Koehlmoos T, Smith R, Yan LL. Research misconduct in low- and middle-income countries. PLoS Med. 2013;10(3):e100315.

32. Amos KA. The ethics of scholarly publishing: exploring differences in plagiarism and duplicate publication across nations. J Med Lib Assoc. 2014;102(2):87-91.
33. Lei L, Zhang Y. Lack of improvement in scientific integrity: an analysis of WOS retractions by Chinese researchers (1997-2006). Sci Eng Ethics. 2017. https://doi.org/10.1007/s11948-017-9962-7.

34. Huh S, Kim SY, Cho H-M. Characteristics of retractions from Korean medical journals in the KoreaMed database: a bibliometric study. PLoS One. 2016. https://doi.org/10.1371/journal.pone.0163588.

35. Kuroki T, Ukawa A. Repeating probability of authors with retracted scientific publications. Accountability Res. 2018;25(4):212-9.

36. Horbach SPJM, Halffman W. The ability of different peer review procedures to flag problematic publications. Scientometrics. 2019;118:339-73.

37. O'Rear AE, Radvansky GA. Failure to accept retractions: a contribution to the continued influence effect. Mem Cogn. 2019. https://doi.org/10. 3758/s13421-019-00967-9.

38. Marasovic T, Utrobicic A, Marusic A. Transparency of retracting and replacing articles [comment]. Lancet. 2018;391:1244-5.

39. Fanelli D, loannidis JPA, Goodman S. Improving the integrity of published science: an expanded taxonomy of retractions and corrections. Eur J Clin Investig. 2018. https://doi.org/10.1111/eci.12898.

40. Decullier E, Maisonneuve H. Correcting the literature: improvement trends seen in contents of retraction notices. BMC Res Notes. 2018;11:490 https://doi.org/10.1186/s13104-018-3576-2.

41. Shuai X, Rollins J, Moulinier I, Custis T, Edmunds M, Schilder F. A multidimensional investigation of the effects of publication retraction on scholarly impact. J Assoc Inf Sci Technol. 2017;68(9):2225-36.

42. Collaborative Working Group. RePAIR consensus guidelines: responsibilities of publishers, agencies, institutions, and researchers in protecting the integrity of the research record. Res Integr Peer Rev. 2018;3:15. https://doi. org/10.1186/s41073-018-0055-1.

\section{Publisher's Note}

Springer Nature remains neutral with regard to jurisdictional claims in published maps and institutional affiliations.

Ready to submit your research? Choose BMC and benefit from:

- fast, convenient online submission

- thorough peer review by experienced researchers in your field

- rapid publication on acceptance

- support for research data, including large and complex data types

- gold Open Access which fosters wider collaboration and increased citations

- maximum visibility for your research: over $100 \mathrm{M}$ website views per year

At BMC, research is always in progress.

Learn more biomedcentral.com/submissions 